\title{
KONSEP PENGUATAN NILAI MORAL ANAK MENURUT KOHLBERG
}

\section{Suparno}

STAI Al-Azhar Menganti Gresik

- - - - - - - - - - - - - - - - - - - - - - - - - - - - - - - - - - - - - - - - - - - - - - - - - - - - -

\begin{abstract}
Abstrak
Masalah moral menjadi sebuah masalah yang sekarang ini sangat banyak meminta perhatian, terutama bagi para pendidik, ulama, pemuka masyarakat dan para orang tua. Banyaknya info tentang criminal kepada anak-anak, seperti yang terjadi di beberapa daerah yang hampir setiap minggu diberitakan di berbagai media, baik media cetak maupun elektronik. dalam tulisan ini ingin lebih banyak konsep nilai moral dari Kohlberg beserta perkembanganya yang akan di integrasikan dengan moral dalam pandagan islam. Hasil menunjukkan bahwa Kohlberg memaparkan dengan Teori yang memandangan bahwa penalaran moral, yang merupakan dasar dari perilaku etis mempunyai enam tahapan perkembangan yang dapat teridentifikasi. Ia mengikuti perkembangan dari keputusan moral seiring penambahan usia yang semula diteliti Piaget, yang menyatakan bahwa logika dan moralitas berkembang melalui tahapan-tahapan konstruktif. Kohlberg memperluas pandangan dasar ini, dengan menentukan bahwa proses perkembangan moral pada prinsipnya berhubungan dengan keadilan dan perkembangannya berlanjut selama kehidupan, walaupun ada dialog yang mempertanyakan implikasi filosofis dari penelitiannya.
\end{abstract}

Kata Kunci: Nilai, Moral, Anak.

\begin{abstract}
Moral issues have become a problem that is currently asking a lot of attention, especially for educators, scholars, community leaders and parents. There is a lot of information about criminals against children, such as what happens in several areas which are reported almost every week in various media, both print and electronic media. In this paper, we want more concepts of moral values from Kohlberg and their developments that will be integrated with morals in Islamic perspective. The results show that Kohlberg explained the theory which holds that moral reasoning, which is the basis of ethical behavior, has six identifiable stages of development. It follows the development of moral decisions with increasing age that Piaget originally studied, who argued that logic and morality develop through constructive stages. Kohlberg extends this basic view, by determining that the process of moral development is principally linked to justice and its development continues throughout life, despite the dialogue that questions the philosophical implications of his research.
\end{abstract}

Keywords: Value, Moral, Children.

Program Studi Pendidikan Guru Madrasah Ibtidaiyah

STAI Al-Azhar Menganti Gresik, Indonesia

\section{Pendahuluan}

Masalah moral merupakan masalah yang sekarang ini sangat banyak meminta perhatian, terutama bagi para pendidik, ulama, pemuka masyarakat dan para orang tua. Tidak henti-hentinya kita mendengar berita tentang tindakan kriminalitas yang dilakukan oleh anakanak, seperti yang terjadi di beberapa daerah yang hampir setiap minggu diberitakan di berbagai media, baik media cetak maupun elektronik. Bagi masyarakat kota bukan suatu hal yang aneh apabila mendengar atau melihat anak-anak sekolah melakukan tawuran (perkelahian antar pelajar) yang tidak sedikit menimbulkan sejumlah korban. Diperlukan waktu yang panjang dan upaya pendidikan yang sungguh-sungguh untuk mengatasi kondisi ini. Pendidikan dalam hal ini diartikan secara luas, yaitu sebagai upaya untuk 
mentransformasikan nilai-nilai, sikap, pengetahuan dan keterampilan tertentu dari generasi sebelumnya kepada generasi berikutnya. Pendidikan merupakan alat strategis untuk membentuk dan mengembangkan nilai, sikap dan moral dari generasi sebelumnya kepada generasi berikutnya. Adapun moral sama dengan etika, atau kesusilaan yang diciptakan oleh akal, adat dan agama, yang memberikan norma tentang bagaimana kita harus hidup.

Nilai moral pada dasarnya adalah mengupayakan anak mempunyai kesadaran dan berprilaku taat moral yang secara otonom berasal dari dalam diri sendiri. Dasar otonomi nilai moral adalah identifikasi dan orientasi diri. Pola hidup keluarga (Ayah dan Ibu) merupakan "Model Ideal" bagi peniruan dan pengindentifikasian perilaku dirinya. Moral menurut para pakar mempunyai definisi yang berbeda-beda. Namun dalam tulisan ini ingin lebih banyak konsep nilai moral dari Kohlberg beserta perkembanganya yang akan di integrasikan dengan moral dalam pandagan islam.

Otomisasi nilai moral dalam diri anak berlangsung dalam dua tahap, yaitu pembiasaan diri dan identifikasian diri. Merujuk pada sistem moral Spranger, nilai-nilai moral yang diupayakan bagi kepemilikan dan pengembangan dasar-dasar disiplin diri mencakup lima nilai, yaitu: nilai-nilai ekonomis, social,politis, Ilmiah, estetis dan agama dalam sistem nilai spranger, nilai etik tidak berdiri sendiri, tetapi sebagai bagian integral dari nilai religi.

Hubungan antara disiplin diri dengan nilai ini merupakan konsep nilai moral yang memungkinkan orang tua untuk membantu anak dalam memiliki dasar disiplin diri. Sebagaimana hasil riset dari Ibda yang menjelaskan bahwa pentingnya pendidikan moral bagi seorang anak adalah untuk menguatkan pengendalian diri individu ke arah yang lebih baik.

\section{A. Pengertian Perkembangan Moral}

(Abdul, 2005) Pengertian perkembangan secara luas menunjuk pada keseluruhan proses perubahan dari potensi yang dimiliki individu dan tampil dalam kualitas kemampuan, sifat dan ciri-ciri yang baru. Helden (1977) dan Richards (1971) berpendapat moral adalah suatu kepekaan dalam pikiran, perasaan, dan tindakan dibandingkan dengan tindakan-tindakan lain yang tidak hanya berupa kepekaan terhadap prinsip-prinsip dan aturan-aturan. Kita telah mengetahui arti dari kedua suku kata yaitu perkembangan dan moral maka selanjutnya yaitu kita mulai memahami arti dari gabungan dua kata tersebut "Perkembangan Moral" Santrock (1995) Perkembangan moral adalah perkembangan yang berkaitan dengan aturan dan konvensi mengenai apa yang seharusnya dilakukan oleh manusia dalam interaksinya dengan orang lain. 
Perkembangan moral adalah perubahan-perubahan perilaku yang terjadi dalam kehidupan anak berkenaan dengan tatacara, kebiasaan, adat, atau standar nilai yang berlaku dalam kelompok sosial.

Moral pada setiap diri manusia adalah sangatlah berbeda, pada dunia psikologi moral disebut superego, sedangkan pada agama islam menyebutnya denga hati nurani atau af'idah yang di dalamnya menunjukkan kehidupan rohania atau spiritual. Pada pemunculan hati nurani adalah ketika orang tua dengan susah payah mendidik dan membimbing anak agar memahami apa dan bagaimana prilaku yang baik dan benar, serta mana dan bagaimana prilaku yang salah dan buruk.karena hati nurani diwarnai, diolah dan dimatangan oleh lingkungan serta pada kematangan mengikuti kematangan perkembangan kepribadian. Pengaruh lingkungan dan norma yang ditanamkan orang tua dan masyarakat menjadi kepribadian.

\section{B. Teori Perkembangan Moral}

Lawrence Kohlberg menjelaskan tahapan perkembangan moral sebagai ukuran dari tinggi rendahnya moral seseorang berdasarkan perkembangan penalaran moralnya.. Tahapan tersebut dibuat saat ia belajar psikologi di University of Chicago berdasarkan teori yang ia buat setelah terinspirasi hasil kerja Jean Piaget dan kekagumannya akan reaksi anak-anak terhadap dilema moral. Ia menulis disertasi doktornya pada tahun 1958 yang menjadi awal dari apa yang sekarang disebut tahapan-tahapan perkembangan moral dari Kohlberg.

Teori ini berpandangan bahwa penalaran moral, yang merupakan dasar dari perilaku etis mempunyai enam tahapan perkembangan yang dapat teridentifikasi. Ia mengikuti perkembangan dari keputusan moral seiring penambahan usia yang semula diteliti Piaget, logika dan moralitas berkembang melalui tahapan-tahapan konstruktif. padangan tersebut di perluas kembali oleh Kohlberg dengan menentukan bahwa proses perkembangan moral pada prinsipnya berhubungan dengan keadilan dan perkembangannya berlanjut selama kehidupan, walaupun ada dialog yang mempertanyakan implikasi filosofis dari penelitiannya.

Kohlberg menggunakan cerita-cerita tentang dilema moral dalam penelitiannya. Ia tertarik bagaimana orang-orang akan menjustifikasi tindakan-tindakan mereka bila mereka berada dalam persoalan moral yang sama. Lawrence Kohlberg menekankan bahwa perkembangan moral didasarkan terutama pada penalaran moral dan berkembang secara bertahap. Konsep kunci dari teori Kohlberg ialah internalisasi, yakni perubahan 
perkembangan dari perilaku yang dikendalikan secara eksternal menjadi perilaku yang dikendalikan secara internal. Kohlberg sampai pada pandangannya setelah 20 tahun melakukan wawancara yang unik dengan anak-anak.

Terdapat hasil wawancara, yang menjadi sebuah cerita dimana tokoh-tokohnya menghadapi dilema-dilema moral. Bagaimana anak-anak dalam menyikapi setiap cerita yang dilakukan oleh masing-masing tokoh dalam cerita yang disampaikan oleh kohlberg. Berikut ini adalah salah satu cerita dilema Kohlberg yang paling populer:

"Di Eropa seorang perempuan hampir meninggal akibat sejenis kanker. Ada suatu obat yang menurut dokter dapat menyelamatkannya. Obat tersebut adalah sejenis radium yang baru-baru ini ditemukan oleh seorang apoteker di kota yang sama. Biaya membuat obat ini sangat mahal, tetapi sang apoteker menetapkan harganya sepuluh kali lipat lebih mahal dari pembuatan obat tersebut. Untuk pembuatan satu dosis kecil obat ia membayar 200 dolar dan menjualnya 2000 dolar. Suami pasien perempuan, Heinz pergi ke setiap orang yang ia kenal untuk meminjam uang, tetapi ia hanya bisa mengumpulkan 1000 dolar atau hanya setengah dari harga obat tersebut. Ia memberitahu apoteker bahwa istrinya sedang sakit dan memohon agar apoteker bersedia menjual obatnya lebih murah atau memperbolehkannya membayar setengahnya kemudian. Tetapi sang apoteker berkata, "Tidak, aku menemukan obat, dan aku harus mendapatkan uang dari obat itu." Heinz menjadi nekat dan membongkar toko obat itu untuk mencuri obat bagi istrinya".

Cerita ini adalah salah satu dari sebelas cerita yang dikembangkan oleh Kohlberg untuk menginvestigasi hakekat pemikiran moral. Setelah membaca cerita, anak-anak menjadi responden menjawab serangkaian pertanyaan tentang dilema moral. Haruskah Heinz mencuri obat? Apakah mencuri obat tersebut benar atau salah? Mengapa? Apakah tugas suami untuk mencuri obat bagi istrinya kalau ia tidak mendapatkannya dengan cara lain? Apakah apoteker memiliki hak untuk mengenakan harga semahal itu walaupun tidak ada suatu aturan hukum yang membatasi harga? Mengapa atau mengapa tidak?. Berdasarkan penalaran tersebut, Kohlberg kemudian mengkategorisasi dan mengklasifikasi respon yang dimunculkan ke dalam enam tahap yang berbeda (Muhammad, 2017).

\section{Tahapan-Tahapan Perkembangan Moral}

Kohlberg memperluas karya piaget yang menentukan bahwa proses perkembangan moral pada prinsipnya berhubungan dengan keadilan, dan itu terus berlangsung sepanjang hidup individu. Ada Enam tahap perkembangan moral Kohlberg. Keenam 
tahapan perkembangan moral dikelompokkan menjadi tiga tingkatan: pra-konvensional moralitas, moralitas konvensional, dan moralitas pasca konvensional.

Tiga Level dan Enam Tahap Penalaran Moral menurut Kohlberg.

\begin{tabular}{|c|c|c|c|}
\hline \multirow{3}{*}{\begin{tabular}{l}
\multicolumn{1}{c}{ Level } \\
Level 1 : Moralitas \\
prakonvensional
\end{tabular}} & Rentang Usia & Tahap & Esensi Penalaran Moral \\
\hline & $\begin{array}{l}\text { Ditemukan pada } \\
\text { anak-anak } \\
\text { prasekolah, } \\
\text { sebagian besar } \\
\text { anak-anak SD, } \\
\text { sejumlah siswa } \\
\text { SMP, dan } \\
\text { segelintir siswa } \\
\text { SMU }\end{array}$ & $\begin{array}{l}\text { Tahap 1 } \\
\text { Hukuman } \\
\text { penghindaran } \\
\text { dan kepatuhan } \\
\text { (Punishment - } \\
\begin{array}{l}\text { avoidance and } \\
\text { obedience) }\end{array}\end{array}$ & $\begin{array}{l}\text { Orang membuat keputusan } \\
\text { berdasarkan apa yang terbaik } \\
\text { bagi mereka, tanpa } \\
\text { mempertimbangkan kebutuhan } \\
\text { atau perasaan orang lain. Orang } \\
\text { mematuhi peraturan hanya jika } \\
\text { peraturan tersebut dibuat oleh } \\
\text { orang-orang yang lebih } \\
\text { berkuasa, dan mereka mungkin } \\
\text { melanggarnya bila mereka } \\
\text { merasa pelanggaran tersebut } \\
\text { tidak ketahuan orang lain. } \\
\text { Perilaku yang "salah" adalah } \\
\text { perilaku yang akan } \\
\text { mendapatkan hukuman }\end{array}$ \\
\hline & & $\begin{array}{l}\text { Tahap 2 : Saling } \\
\text { memberi dan } \\
\text { menerima } \\
\text { (Exchange of } \\
\text { favors) }\end{array}$ & $\begin{array}{l}\text { (Syamsu, 2011) Orang } \\
\text { memahami bahwa orang lain } \\
\text { juga memiliki kebutuhan. } \\
\text { Mereka mungkin mencoba } \\
\text { memuaskan kebutuhan orang } \\
\text { lain apabila kebutuhan mereka } \\
\text { sendiri pun akan memenuhi } \\
\text { perbuatan tersebut ("bila kamu } \\
\text { mau memijat punggungku; aku } \\
\text { pun akan memijat } \\
\text { punggungmu"). Mereka masih } \\
\text { mendefinisikan yang benar dan } \\
\text { yang salah berdasarkan } \\
\text { konsekuensinya bagi diri } \\
\text { mereka sendiri. }\end{array}$ \\
\hline $\begin{array}{l}\text { Level } 2 \text { : Moralitas } \\
\text { konvensional }\end{array}$ & $\begin{array}{l}\text { Ditemukan pada } \\
\text { segelintir siswa } \\
\text { SD tingkat } \\
\text { akhir, sejumlah } \\
\text { siswa SMP, dan } \\
\text { banyak siswa } \\
\text { SMU (Tahap } 4 \\
\text { biasanya tidak } \\
\text { muncul sebelum } \\
\text { masa SMU) }\end{array}$ & 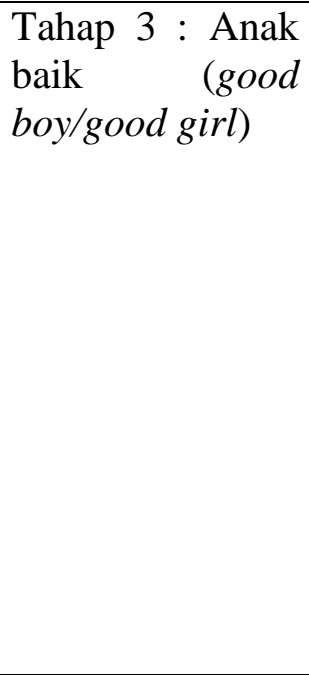 & $\begin{array}{l}\text { Orang membuat keputusan } \\
\text { melakukan tindakan tertentu } \\
\text { semata-mata } \\
\text { menyenangkan orang lain, } \\
\text { terutama tokoh-tokoh yang } \\
\text { memiliki otoritas (seperti guru, } \\
\text { teman sebaya yang populer). } \\
\text { Mereka sangat peduli pada } \\
\text { terjaganya hubungan } \\
\text { persahabatan melalui sharing, } \\
\text { kepercayaan, dan kesetiaan, } \\
\text { dan juga mempertimbangkan } \\
\text { perspektif serta maksud orang } \\
\text { lain ketika membuat keputusan. }\end{array}$ \\
\hline
\end{tabular}




\begin{tabular}{|c|c|c|c|}
\hline & & $\begin{array}{l}\text { Tahap } 4 \text { : } \\
\text { Hukum dan tata } \\
\text { tertib (Law and } \\
\text { keteraturan). }\end{array}$ & $\begin{array}{l}\text { Orang memandang masyarakat } \\
\text { sebagai suatu tindakan yang } \\
\text { utuh yang menyediakan } \\
\text { pedoman bagi perilaku. Mereka } \\
\text { memahami bahwa peraturan itu } \\
\text { penting untuk menjamin } \\
\text { berjalan harmonisnya } \\
\text { kehidupan bersama, dan } \\
\text { meyakini bahwa tugas mereka } \\
\text { adalah mematuhi peraturan- } \\
\text { peraturan tersebut. Meskipun } \\
\text { begitu, mereka menganggap } \\
\text { peraturan itu bersifat kaku } \\
\text { (tidak fleksibel); mereka belum } \\
\text { menyadari bahwa sebagaimana } \\
\text { kebutuhan masyarakat berubah- } \\
\text { ubah, peraturan pun juga } \\
\text { seharusnya berubah. }\end{array}$ \\
\hline $\begin{array}{l}\text { Level } 3 \text { : Moralitas } \\
\text { postkonvensional }\end{array}$ & $\begin{array}{lr}\text { Jarang } & \text { muncul } \\
\text { sebelum } & \text { masa } \\
\text { kuliah } & \end{array}$ & $\begin{array}{lc}\text { Tahap } & 5 \\
\text { Kontrak } & \text { Sosial } \\
\text { (Social contract). }\end{array}$ & $\begin{array}{lr}\text { Orang memahami } & \text { bahwa } \\
\text { peraturan-peraturan yang ada } \\
\text { merupakan representasi dari } \\
\text { persetujuan banyak individu } \\
\text { mengenai perilaku } \text { yang } \\
\text { dianggap tepat. Peraturan } \\
\text { dipandang sebagai mekanisme } \\
\text { yang bermanfaat untuk } \\
\text { memelihara keteraturan social } \\
\text { dan melindungi hak-hak } \\
\text { individu, alih-alih sebgai } \\
\text { perintah yang bersifat mutlak } \\
\text { yang harus dipatuhi semata- } \\
\text { mata karena merupakan } \\
\text { "hukum". } \text { Orang juga } \\
\text { memahami fleksibilitas sebuah } \\
\text { peraturan; peraturan yang tidak } \\
\text { lagi mengakomodasi kebutuhan } \\
\text { terpenting masyarakat bisa dan } \\
\text { harus dirubah. }\end{array}$ \\
\hline & & \begin{tabular}{lr} 
Tingkat & \multicolumn{1}{c}{ : } \\
Prinsip etika & \\
universal & (tahap \\
ideal & yang \\
bersifat & \\
hipotetis, yang \\
hanya dicapai \\
segelintir orang)
\end{tabular} & $\begin{array}{l}\text { Kebenaran ditentukan oleh } \\
\text { keputusan kata hati, sesuai } \\
\text { dengan prinsip-prinsip etika } \\
\text { yang logis, universal dan } \\
\text { konsistensi. Prinsip-prinsip } \\
\text { etika universal bersifat abstrak, } \\
\text { seperti keadilan (misalnya, } \\
\text { kesetaraan semua orang, } \\
\text { penghargaan terhadap harkat } \\
\text { dan martabat manusia, } \\
\text { komitmen pada keadilan) yang } \\
\text { melampaui norma-normadan }\end{array}$ \\
\hline
\end{tabular}




\begin{tabular}{|l|l|l|}
\hline & & 64 \\
& & peraturan-peraturan yang \\
& spesifik. Mereka sangat \\
mengikut hati nurani dan \\
karena itu bisa saja melawan \\
peraturan yang bertentangan \\
dengan prinsip-prinsip etis \\
mereka sendiri (Muhibbin, \\
\end{tabular}

Alhasil menurut Kolberg kejadian perkembangan sosial dan moral pada diri siswa terjadi pada tiga tingkatan besar:

1. Tingkat moral Prakonvensional, yang terbagi menjadi dua tahapan:

a. Tahap 1, memperhatikan ketaatan dan hukuman, Sebuah contoh Ketika seorang siswa harus mematuhi perintah dari gurunya agar tidak mendapatkan hukuman. Dan Seorang siswa rajin belajar agar dia bisa menjadi seorang juara kelas (Alifiaz, 2020)

b. Tahap 2, memperhatikan pemuasan kebutuhan, Contoh dari kepentingan pribadi didorong adalah ketika seorang anak diminta oleh orang tuanya untuk melakukan tugas. Anak bertanya "apa untungnya bagi saya?" Orang tua akan menawarkan anak insentif dengan memberikan anak uang saku untuk membayar mereka untuk tugas-tugas mereka. Anak termotivasi untuk melakukan pekerjaan untuk kepentingan pribadi.

2. Moralitas konvensional, juga terbagi menjadi dua bagian yaitu:

a. Tahap 3, Memperbaiki citra "anak baik" seperti contoh mereka mencoba untuk menjadi "anak baik" atau "gadis yang baik" untuk memenuhi harapan tersebut, setelah mengetahui bahwa yang dianggap sebagai manfaat yang baik diri.

b. Tahap 4, Memperhatikan hukuman dan peraturan, otoritas dan tatanan sosial ketaatan driven, adalah penting untuk mematuhi hukum, keputusan, dan konvensi sosial karena berguna dalam memelihara fungsi dari masyarakat. Penalaran moral dalam tahap empat lebih dari sekedar kebutuhan akan penerimaan individual dalam tahap tiga. Sebuah cita-cita pusat atau cita-cita sering meresepkan apa yang benar dan yang salah.

3. Moralitas pascakonvensional, juga terbagi mejadi dua yaitu;

a. Tahap 5, Memperhatikan hak persorangan, karena didorong kontrak sosial, dunia dipandang sebagai memiliki pendapat-pendapat yang berbeda, hak dan nilai-nilai. Perspektif tersebut harus saling dihormati sebagai unik untuk setiap orang atau 
masyarakat. Hukum dianggap sebagai kontrak sosial, bukan fatwa yang kaku. Mereka yang tidak memajukan kesejahteraan umum harus diubah bila perlu demi terpenuhinya "kebaikan terbesar untuk jumlah terbesar orang." Hal ini dicapai melalui keputusan mayoritas dan kompromi tak terelakkan.

b. Tahap 6, Memperhatikan prinsip-prinsip etika, prinsip etika universal driven), penalaran moral didasarkan pada penalaran abstrak menggunakan prinsip-prinsip etis universal. Hukum hanya berlaku sejauh mereka didasarkan pada keadilan, dan komitmen terhadap keadilan juga menyertakan keharusan untuk tidak mematuhi hukum yang tidak adil. Hak hukum tidak diperlukan, sebagai kontrak sosial dan tidak penting untuk tindakan moral deontis.

\section{Aplikasi Teori Perkembangan Moral}

(Sutomo, 2009) moral memiliki keterkaitan dengan perkembangan Ilmu Pengetahuan Alam. Perkembangan Ilmu Pengetahuan Alam yang semakin pesat memiliki dua wajah yang berkebalikan. Satu sisi memiliki tujuan positif yaitu untuk kesejahteraan manusia, namun sisi negatif lainnya adalah IPA tanpa dilandasi moral akan menghilangkan tujuan utama tersebut atau bahkan menghilangkan eksistensi manusia. Jadi jelaslah bahwa yang mengendalikan IPA adalah pelaksana IPA itu sendiri yang diharapkan memiliki komotmen tinggi dalam mengaplikasikan moral dan etika dalam setiap tingkah-lakunya.

\section{Gambar 1.Peran Moral dalam Wajah IPA}

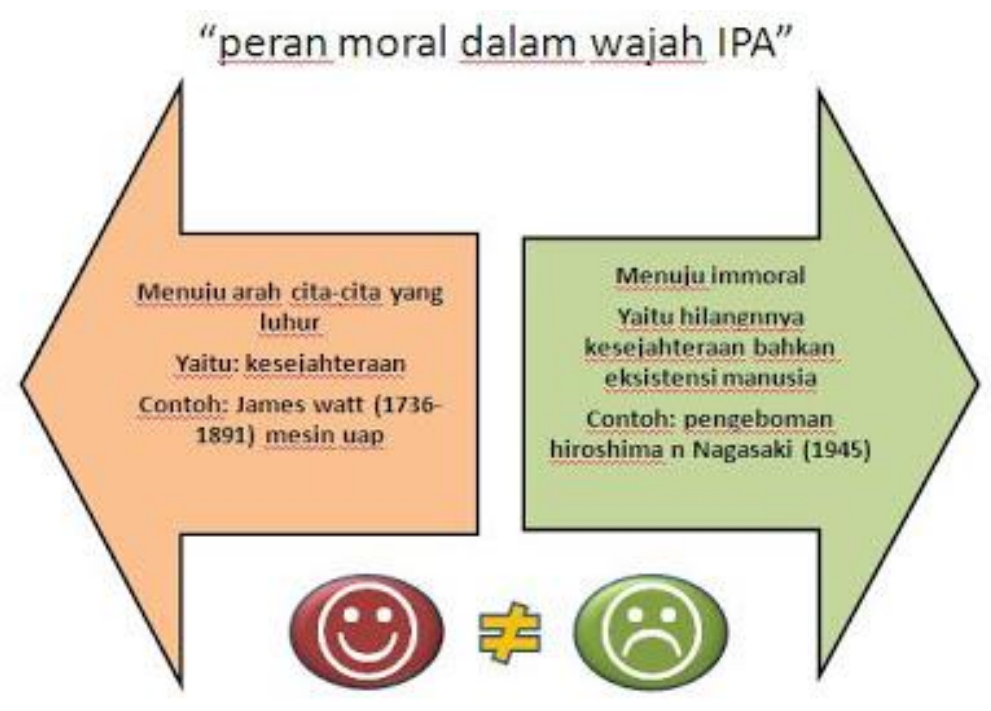

Sebagai gambaran, tidak dapat dipungkiri sejak James Watt (1736-1819) menemukan mesin uap (yang praktis), maka dunia permesinan terus berkembang, karena 
mesin uap tersebut menjadi dasar munculnya mesin-mesin yang lain. Akibatnya terjadilah masa kejayaan dengan revolusi industry yang berkelanjutan, sehingga kesejahteraan terjadi dimana-mana. Karena sifat ilmu kealaman yang bersifat dinamis selalu berkembang, maka banyak orang menaruh harapan kepada IPA agar kedepan semakin banyak temuan baru yang tentunya semakin meningkatkan kesejahteraan bagi umat manusia.

Berkebalikan dengan kesuksesan IPA dalam hal mensejahterakan umat manusia, bom atom di Heroshima dan Nagasaki pada 6 dan 9 Agustus tahun 1945, yang menelan korban meninggal sebanyak 266.575 orang, membuat wajah ilmu kealaman tercoreng sebagai ilmu pemusnah missal dan penghancur. Jika dikaji lebih dalam maka kesalahan bukan terletak pada ilmu kealaman, namun pada oknum pelaksana ilmu kealaman tersebut yang bersifat immoral.

Moral perlu mendapatkan perhatian yang khusus dari para pelaku ilmu kealaman dan manusia secara umum. Moral dan IPA seharusnya tidak bisa dipisahkan demi citacita kemanusiaan yang luhur, yaitu kesejahteraan tetap terjaga. Keterkaitan antara moral dan IPA sebenarnya telah diisyaratkan oleh Albert Einstein yang pada tahun 1915 menemukan teori relativitas, bahwa "science without religion is blind-religion without science is limp", ilmu kealaman tanpa agama adalah buta dan agama tanpa ilmu kealaman adalah lumpun. Hal itu menunjukkan bahwa keterkaitan antara IPA dan moral begitu jelas terlihat, IPA tidak bebas nilai dan tidak lepas kendali, tetapi memiliki tanggung jawab moral terhadap Tuhan pencipta alam dan terhadap kemanusiaan (Dankzoma, 2020).

\section{Simpulan}

Kohlberg memaparkan dengan Teori yang memandangan bahwa penalaran moral, yang merupakan dasar dari perilaku etis mempunyai enam tahapan perkembangan yang dapat teridentifikasi. Ia mengikuti perkembangan dari keputusan moral seiring penambahan usia yang semula diteliti Piaget, yang menyatakan bahwa logika dan moralitas berkembang melalui tahapantahapan konstruktif. Kohlberg memperluas pandangan dasar ini, dengan menentukan bahwa proses perkembangan moral pada prinsipnya berhubungan dengan keadilan dan perkembangannya berlanjut selama kehidupan, walaupun ada dialog yang mempertanyakan implikasi filosofis dari penelitiannya. Pada tahap perkembangan moral Kohlberg. Terbagi menjadi enam tahapan perkembangan moral dikelompokkan menjadi tiga tingkatan: 1) pra-konvensional moralitas, 2) moralitas konvensional, 3) moralitas pasca konvensional 
ZAHRA: Research And Tought Elmentary School Of Islam Journal Vol. (1) (2), (Agustus)(2020), (Halaman)(58-67)|

\section{Daftar Pustaka}

Alifiaz. (2017). Perkembanagan Moral Menurut Lawrance dalam http://alifiaz.blogspot.co.id/2013/04/perkembangan-moral-menurut-lawrence.html (22

Aziz, A. A. (2005). Psikologi Agama Kepribadian Muslim Pancasila. Bandung: Algesindo.

Dankzoma. (2017). Teori Perkembangan Moral. http://dankbioma.blogspot.co.id/2013/04/teoriperkembangan-moral-serta_1612.html diakses (20

Kholil, A. (2013). Spiritualitas Khidir (Moralitas Islam Dalam Tindakan Sosial). Ulul Albab Jurnal Studi Islam.

Syah, M. (2004). Psikologi Belajar. Jakarta: Raja Grafindo.

Syamsuddin, M. (2017). Teori Perkembangan Moral dalam http://muhammadsyamsuddin.blogspot.co.id/2012/11/teori-perkembangan-moralkohlberg.html

Yusuf LN, S. (2011). Psikologi Perkembangan Anak dan Remaja. Bandung: Rosda Karya. 